\title{
Penerapan Search Engine Optimization Untuk Meningkatkan Peringkat Website Pada Search Engine Results Page Google (Studi Kasus: www.superbengkel.co.id)
}

\author{
Fabriyan Fandi Dwi Imaniawan $^{1 *}$, Ragil Wijianto ${ }^{2}$, Joko Dwi Mulyanto ${ }^{3}$ \\ ${ }^{1,2,3}$ Sistem Informasi, STMIK Nusa Mandiri \\ Indonesia \\ *Corresponding Author.E-mail:fabriyan.fbf@nusamandiri.ac.id
}

\begin{abstract}
The development of internet-based technology has become a media for spreading information which is faster and more efficient than other media, such as print and electronic media. It is what drives a number of business owners to start exploring the digital world by opening websites and social media to promote their businesses. Multi Jaya Press is a company in Banyumas Regency which is engaged in the sale of motorcycle press tool and workshop installation services. In the marketing process,, Multi Jaya Press uses media in the form of a website which is located at www.superbengkel.co.id. The use of the website is still not optimal for searching several targeted keywords, thus the website is difficult to be found by the google search engine organically. Generally, a website owner will make a quick decision to solve this problem using paid Google ads. Although it can appear on the top page of google search, the use of paid Google ads will cost a lot of money. It is clearly seen when a website uses google ads, it will be labeled as an "advertisement". Therefore, a suitable strategy is needed to increase the position of keywords on the website www.superbengkel.co.id on the Google search page or the Search Engine Results Page (SERP). One of that strategy is the use of Search Engine Optimization (SEO). The result of this research is that the website appears on the start page of Google search with the targeted keywords.
\end{abstract}

Keywords: Website, Search Engine Optimization, SEO, Google, SERP

\begin{abstract}
Abstrak
Perkembangan teknologi berbasis internet menjadi media penyebaran informasi yang lebih cepat dan efisien dibandingkan media lain seperti media cetak dan elektronik. Hal inilah yang menggerakan sejumlah pemilik bisnis untuk mulai merambah dunia digital dengan membuka website maupun media sosial untuk mempromosikan usaha mereka. Multi Jaya Press merupakan salah satu perusahaan di Kabupaten Banyumas yang bergerak dalam bidang penjualan alat press sepeda motor dan jasa instalasi bengkel. Dalam pemasarannya, Multi Jaya Press menggunakan media berupa website yang beralamat di www.superbengkel.co.id. Penggunaan website ini pun masih belum optimal, terutama dalam pencarian beberapa kata kunci yang ditargetkan. Hal ini menyebabkan website sulit ditemukan oleh mesin pencari google secara organik. Umumnya, seorang pemilik website akan mengambil keputusan secara cepat untuk mengatasi permasalahan tersebut yaitu dengan menggunakan iklan berbayar dari google. Meskipun dapat tampil di halaman teratas pencarian google, akan tetapi penggunaan iklan seperti ini akan memakan biaya yang tidak sedikit. Terlebih ketika sebuah website menggunakan iklan dari google, maka akan dilabeli 'iklan' yang memungkinkan pengguna google lain tidak mau mengunjungi website tersebut. Oleh karena itu, diperlukan strategi yang cocok untuk menaikkan posisi kata kunci pada
\end{abstract}


website www.superbengkel.co.id di halaman pencarian google atau Search Engine Results Page (SERP), salah satunya dengan menggunakan Search Engine Optimization (SEO). Hasil dari penelitian ini adalah website muncul di halaman awal pencarian google dengan kata kunci yang ditargetkan.

Kata Kunci: Website, Search Engine Optimization, SEO, Google, SERP

\section{Pendahuluan}

Berkembangnya informasi saat ini memaksa orang agar lebih responsif terhadap perkembangan teknologi informasi yang ada. Peran teknologi informasi sangatlah penting dalam berbagai bidang. Layaknya sebuah kebutuhan pokok, informasi sangat cepat diakses kapanpun dan dimanapun. Apalagi dengan hadirnya internet di kalangan masyarakat. Semua informasi dapat diperoleh tanpa batasan apapun.

Saat ini, mayoritas pengguna internet memanfaatkan search engine atau mesin pencari sebagai alat dalam mencari informasi. Search engine memudahkan pengguna internet mencari beragam informasi yang dibutuhkan hanya dengan menggunakan kata kunci dalam proses pencariannya.

Menurut (Laksana \& Syahara, 2018), ada beberapa search engine yang dapat digunakan sebagai sumber pencarian informasi bagi pengguna internet, yaitu: Bing, Yahoo, Yippy, Aol, Google, Yandex, Kiddle, Ask, Duckduckgo, Baidu dan StarPage.

Berdasarkan situs Alexa.com, Google menempati urutan pertama pada daftar situs yang paling banyak diakses oleh pengguna internet (Alexa Top Sites, 2020)

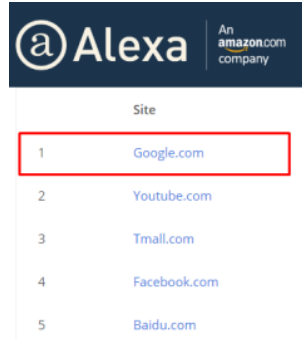

Gambar 1. Alexa Top Sites

Selain itu, menurut situs similarweb.com pun menunjukkan bahwa Google menjadi situs yang paling banyak dikunjungi oleh pengguna internet di dunia (Top 50 Most Visited Websites Ranked - SimilarWeb, 2020).

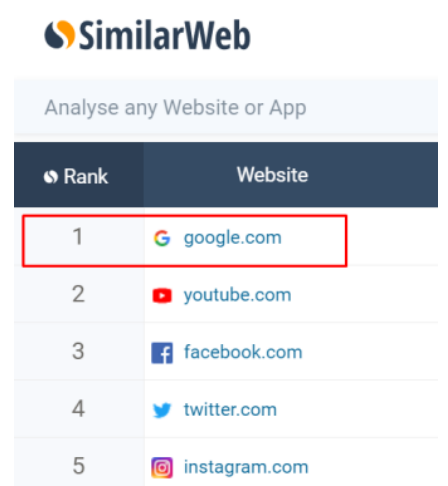

Gambar 2. Similarweb Top Website

Dari kedua data tersebut dapat disimpulkan bahwa Google.com menempati urutan pertama sebagai search engine yang paling banyak diakses di Dunia.

Penggunaan situs mesin pencari 
Google.com sebagai fasilitator yang paling banyak digunakan dalam memudahkan dan mempercepat pencarian sebuah informasi inilah yang membuat peneliti tertarik untuk melakukan penelitian yang berusaha mengetahui ada atau tidaknya pengaruh penggunaan mesin pencari Google.com untuk memenuhi kebutuhan informasi.

Multi Jaya Press merupakan salah satu perusahaan di Kabupaten Banyumas yang bergerak dalam bidang otomotif, khususnya dalam memproduksi mesin press velg, press body dan instalasi bengkel motor. Dalam pemasarannya tidak hanya dilakukan secara offline saja, namun juga dilakukan secara online melalui sebuah website yang beralamat di www.superbengkel.co.id.

Namun, selain umur website yang masih tergolong baru, penggunaan website ini masih belum maksimal, terutama dalam Search Engine Result Page (SERP) Google pada beberapa kata kunci yang ditargetkan.

Adapun pada saat penelitian ini diajukan, posisi kata kunci yang ditargetkan pada situs www.superbengkel.co.id dalam SERP Google dapat dilihat pada tabel berikut:

Tabel 1. Posisi Awal Kata Kunci

\begin{tabular}{|c|c|}
\hline Kata Kunci & Posisi SERP \\
\hline Setup Bengkel & $>100$ \\
\hline Harga Press Body Motor & $>100$ \\
\hline Jasa Press Velg Motor & $>100$ \\
\hline
\end{tabular}

Sumber: Google.com (2020)
Berdasarkan data di atas, posisi kata kunci yang ditargetkan situs www.superbengkel.co.id sangat belum optimal dan jauh dari persaingan. Hal ini menyebabkan website sulit ditemukan pada SERP Google. Maka diperlukan riset terhadap penerapan Search Engine Optimization (SEO) yang akurat untuk mengoptimalkan target pengunjung sebuah website. SEO adalah teknik yang digunakan untuk memaksimalkan suatu website agar lebih dikenal atau lebih mudah dibaca oleh search engine untuk menaikkan peringkat pada mesin pencari sehingga banyak pengunjung. (Riyanto \& Purwadi, 2016)

Secara logis, website yang menempati posisi teratas pada hasil pencarian memiliki peluang lebih besar untuk mendapatkan pengunjung. Salah satu metode yang dapat digunakan untuk mencapai hal tersebut adalah dengan menerapkan metode SEO. Tujuan dari penelitian ini adalah menerapkan atau mengimplementasikan SEO agar website www.superbengkel.co.id muncul di halaman awal pencarian google sehingga dapat meningkatkan kunjungan secara organik tanpa menggunakan layanan iklan berbayar dari google.

Dalam penelitian yang dilakukan oleh (Abdurrahman, 2014), untuk menganalisis pengaruh kata kunci kompetitif, Abdurrahman menggunakan Tools SEO, 
Traffic Overview dan Page View. Dengan menguji 2 jenis kata kunci yang kompetitif, diketahui bahwa website yang mengunakan kata kunci kompetitif rendah memiliki perkembangan SEO yang lebih baik sehingga tingkat visibility yang dimiliki website tersebut lebih baik. Sedangkan, website dengan kata kunci kompetitif tinggi memiliki traffic kunjungan website yang lebih baik sehingga tingkat popularitas yang dimiliki website tersebut lebih baik.

(Himawan et al., 2015) mengemukakan bahwa terdapat banyak cara yang dapat digunakan untuk meningkatkan jumlah kunjungan pada sebuah halaman website khususnya toko online, salah satu diantaranya dengan menggunakan blog dan optimasi mesin pencari. Dari hasil penelitian yang dilakukan Himawan dkk, dapat disimpulkan bahwa penggunaan teknik SEO pada website e-commerce memang menunjukkan peningkatan dalam hal trafik kunjungan dan juga peringkat website. Namun demikian pada akhirnya jumlah pengunjung yang banyak belum tentu menghasilkan keuntungan atau profit bagi website e-commerce tersebut.

(Sutanto \& Mulyani, 2015) memaparkan bahwa untuk memasarkan produk-produk UMKM yang efektif tidak bisa dengan hanya mengandalkan sistem pemasaran dan penjualan online melalui web. Namun sistem pemasaran dan penjualan online dapat memanfaatkan teknik optimisasi pada mesin pencari yang dikenal dengan SEO (Search Engine Optimization). Dari penelitian yang dilakukan oleh Sutanto dan Mulyani, terbukti penggunaan model Content Management System (CMS) dapat membantu UMKM dalam menginformasikan produk secara mudah dan penerapan SEO On Page dapat membantu informasi di website agar dikenali oleh mesin pencari.

\section{Metode Penelitian}

\subsection{Konsep Penelitian}

Setiap tahapan dalam penerapan SEO memerlukan cara kerja dengan melewati setiap fase, adapun diagram alir optimasi yang akan dilakukan meliputi beberapa fase yang dapat dilihat pada Gambar 1.

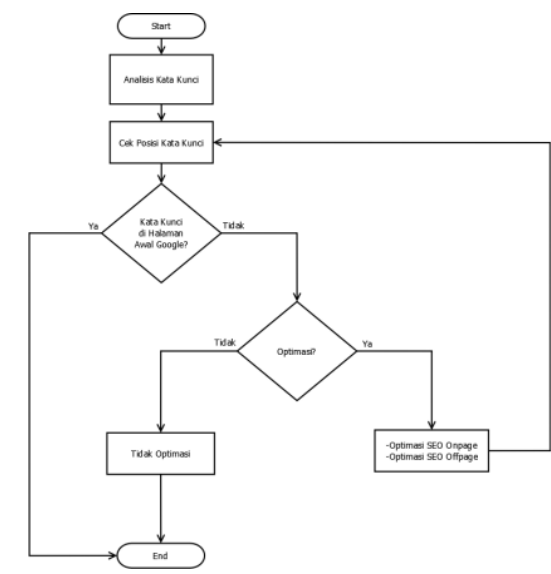

Gambar 3. Diagram Alir Optimasi

Pada gambar 1. menerangkan bahwa proses optimasi dimulai dari Analisis Kata Kunci menggunakan Google Keyword Planner. Fungsi analisis kata kunci adalah untuk mengetahui jumlah penelusuran dan tingkat persaingan kata kunci yang 
ditargetkan. Kemudian melakukan cek posisi kata kunci yang ditargetkan pada mesin pencari google untuk mengetahui apakah sudah berada di halaman awal pencarian google. Apabila kata kunci yang ditargetkan belum berada di halaman awal pencarian google maka akan diterapkan proses optimasi meliputi SEO Onpage dan SEO Offpage. Setelah proses optimasi, dilakukan pengujian dengan cara melakukan pengecekan posisi kata kunci yang ditargetkan pada mesin pencari google. Apabila kata kunci yang ditargetkan masih belum optimal, maka akan dilakukan proses optimasi kembali hingga kata kunci yang ditargetkan berada di halaman awal mesin pencari google.

\subsection{Analisis Data}

Dalam penelitian ini, dibutuhkan beberapa tools analisis data antara lain:

a. Google Keyword Planner

Tools ini digunakan untuk mengetahui tingkat persaingan sebuah kata kunci dan volume pencarian per bulan.

b. Google Webmaster Tools

Tools ini digunakan untuk melakukan beberapa analisis terhadap sebuah website yang meliputi analisis tingkah laku mesin pencari ketika membaca konten yang dimuat dalam website, analisis link internal dan eksternal yang menuju ke website, tools ini juga digunakan untuk melakukan submit sitemap website terhadap mesin pencari google serta melakukan analisis terhadap navigasi website.

c. Google.com.

Mesin pencari google digunakan untuk melakukan analisis terhadap hasil optimasi website.

\subsection{Tahapan Penelitian}

Tahapan yang dilakukan dalam proses optimasi situs www.superbengkel.co.id:

a. SEO Onpage

Tahap optimasi yang dilakukan dari sisi internal website dengan cara mengoptimalkan semua komponen halaman website. Dalam hal ini, situs www.superbengkel.co.id dibangun menggunakan Content Management System (CMS) yaitu Wordpress. CMS Wordpress merupakan aplikasi yang dapat digunakan untuk membuat artikel post, halaman statis, menu, tanpa perlu memikirkan bahasa pemrograman yang rumit (Aini \& Pribadi, 2017). Oleh karena itu, SEO Onpage yang dilakukan meliputi:

1) Optimasi Judul Situs dan Slogan

2) Optimasi Permalink

3) Optimasi Plugin

4) Optimasi Konten
a) Judul
b) URL 

c) Deskripsi
d) Kata Kunci
e) Gambar
f) Internal Link

\section{b. SEO Offpage}

Tahap optimasi yang dilakukan dari sisi eksternal website. SEO Offpage sangat penting bagi sebuah website. SEO Offpage dapat diibaratkan sebagai rekomendasi link yang diberikan website lain atau biasa disebut juga backlink. Langkah-langkah SEO Offpage yang dilakukan pada penelitian ini antara lain:

1) Mendaftar di Google Webmaster

2) Share Link di media sosial

3) Berkomentar di situs yang memiliki otoritas domain tinggi

4) Memposting artikel di situs populer

5) Memposting artikel di PBN (Private Blog Network)

\section{Hasil dan Pembahasan}

\subsection{Analisis Kata Kunci}

Penerapan SEO pada situs www.superbengkel.co.id diawali dengan melakukan analisis kata kunci menggunakan tools Google Keyword Planner. Dalam penelitian ini terdapat tiga kata kunci yang ditargetkan yaitu "Setup Bengkel", "Harga Press Body Motor" dan “Jasa Press Velg Motor”. Untuk mengetahui jumlah penelusuran terhadap dua kata kunci tersebut, maka terlebih dahulu perlu diketahui volume penelusuran kata kunci oleh pengunjung pada halaman pencarian google 12 bulan yang lalu atau dari bulan september 2019 hingga Agustus 2020.

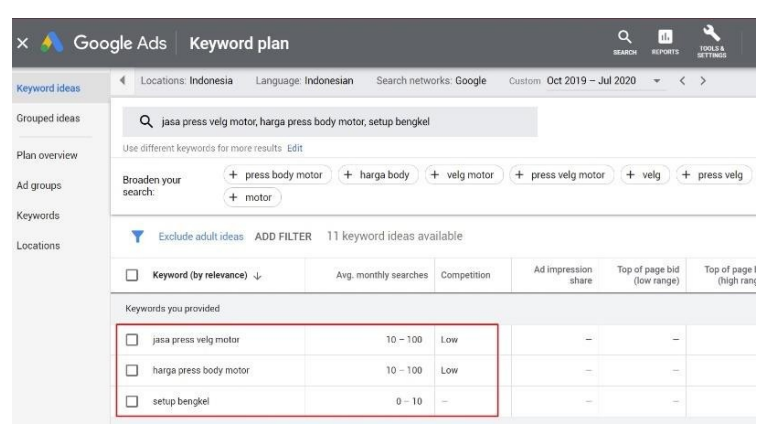

Gambar 4. Volume Penelusuran 3 Kata Kunci Yang Ditargetkan

Pada gambar di atas menunjukkan data trafik per bulan untuk dua kata kunci yang ditargetkan pada situs www.superbengkel.co.id dimana ketiga kata kunci berada dalam tingkat persaingan yang 'sedang' dengan rata-rata per bulan mencapai 10 hingga 100 penelusuran di halaman pencarian google.

\subsection{Penerapan SEO Onpage}

Setelah mengetahui jumlah penelusuran dan tingkat persaingan kata kunci yang ditargetkan, tahapan selanjutnya adalah menerapkan SEO Onpage pada situs www.superbengkel.co.id, meliputi:

a. Optimasi Judul Situs \& Slogan

Langkah awal dalam penerapan SEO pada situs www.superbengkel.co.id adalah dengan mengatur judul situs dan 
slogan. Judul situs akan tampil pada mesin pencari google sebagai judul website, sedangkan slogan akan tampil sebagai deskripsi website.

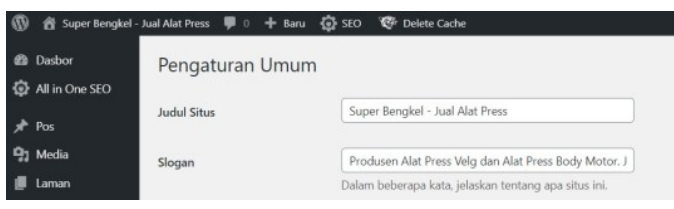

Gambar 5. Pengaturan Judul Situs dan

\section{Slogan}

b. Optimasi Permalink

Langkah kedua yaitu menentukan permalink atau susunan link yang mengarah ke postingan artikel website. Struktur permalink menjadi semacam identitas atau rujukan untuk mesin pencari.

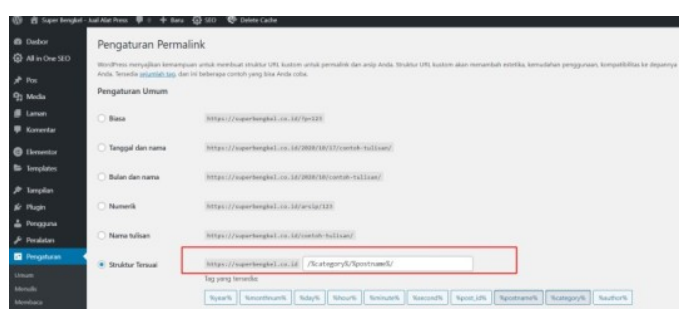

Gambar 6. Pengaturan Permalink

c. Optimasi Plugin

Langkah ketiga yaitu menginstall plugin pendukung pada situs www.superbengkel.co.id. Beberapa plugin SEO yang diinstall antara lain:

1) WP Fastest Cache

Plugin ini berfungsi untuk mengoptimalkan kecepatan loading website.

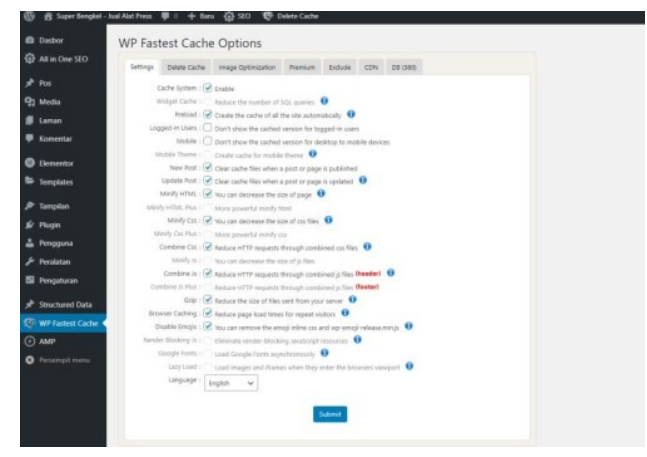

Gambar 7. Pengaturan Plugin WP

Fastest Cache

2) All in One SEO

Plugin ini berfungsi untuk mengoptimalkan pengaturan SEO pada website.

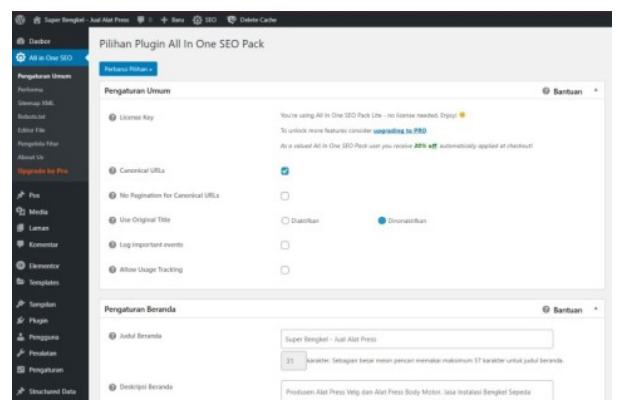

Gambar 8. Pengaturan Plugin All in One SEO

d. Optimasi Artikel

Langkah terakhir pada tahap SEO Onpage adalah mengoptimasi artikel website. Hal yang dilakukan antara lain:

1) Menggunakan kata kunci yang ditargetkan pada judul dan permalink artikel.

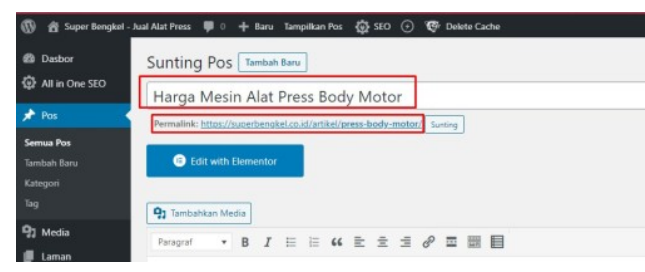

Gambar 9. Pengaturan Judul dan Permalink pada Artikel 
2) Menyisipkan kata kunci pada awal paragraf pertama Artikel

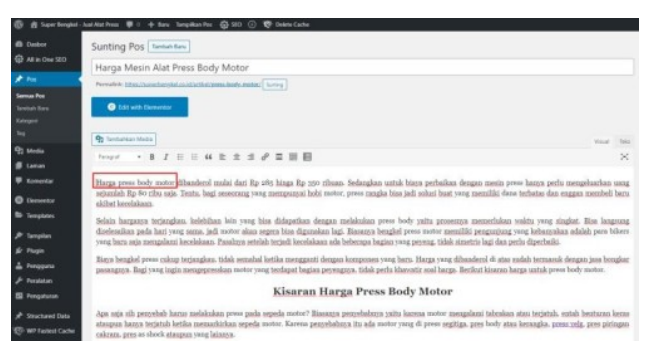

Gambar 10. Pengaturan Awal

\section{Paragraf}

3) Menambahkan teks alternatif dan keterangan gambar pada artikel yang mengandung kata kunci

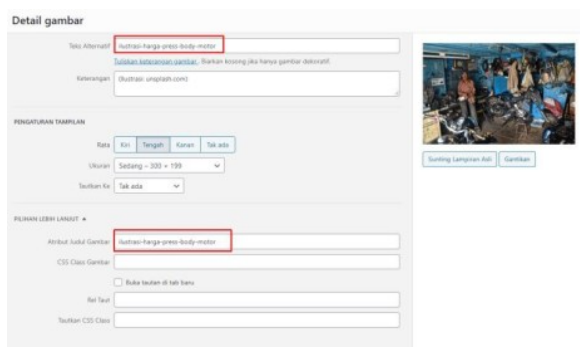

Gambar 11. Pengaturan Teks Alternatif dan Keterangan Gambar

\subsection{Penerapan SEO Offpage}

Setelah pengaturan dari internal website dilakukan, langkah selanjutnya adalah menerapkan SEO Offpage. Langkahlangkah yang dilakukan antara lain:

a. Mendaftar di Google Webmaster

Langkah awal SEO Offpage adalah dengan mendaftarkan website ke Google Webmaster. Google Webmaster merupakan tools dari pihak google yang digunakan untuk menganalisis perkembangan website. Tools ini beralamat di

https://www.google.com/webmasters/

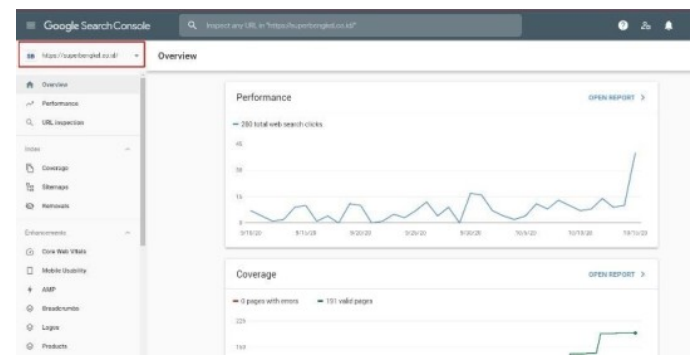

Gambar 12. Tampilan Google Webmasters Tools

b. Share Link di Media Sosial

Langkah kedua adalah membagikan link website ke beberapa media sosial seperti facebook, twitter, pinterest dsb. Berikut contoh penerapannya:

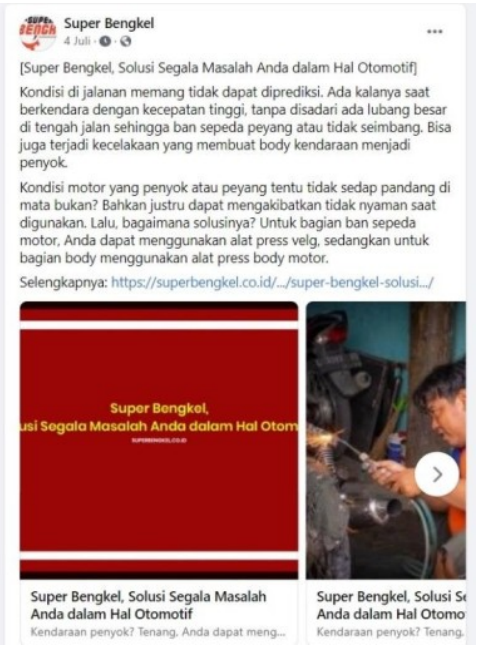

Gambar 13. Share Link di Facebook

c. Berkomentar di situs yang memiliki otoritas domain tinggi

Langkah ketiga adalah membuat komentar yang mengandung kata kunci yang ditargetkan di situs yang memiliki otoritas domain tinggi. Kata kunci ini diarahkan ke situs www.superbengkel.co.id. Contoh situs yang memiliki otoritas tinggi adalah situs-situs pemerintah yang berekstensi .edu, .go.id, .ac.id, .sch.id dan 
sebagainya. Berikut salah satu penerapannya:

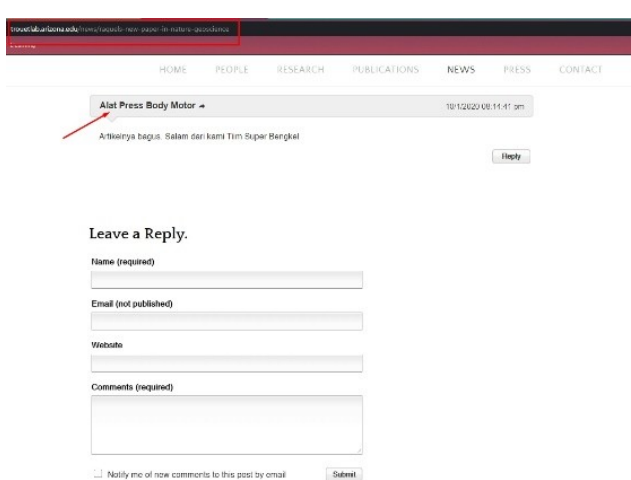

Gambar 14. Komentar di situs trouetlab.arizona.edu

d. Memposting artikel di situs populer

Langkah keempat adalah membuat tulisan yang relevan dengan website di beberapa situs populer seperti kompasiana.com, medium.com, detik.com dsb. Contoh artikel di kompasiana.com

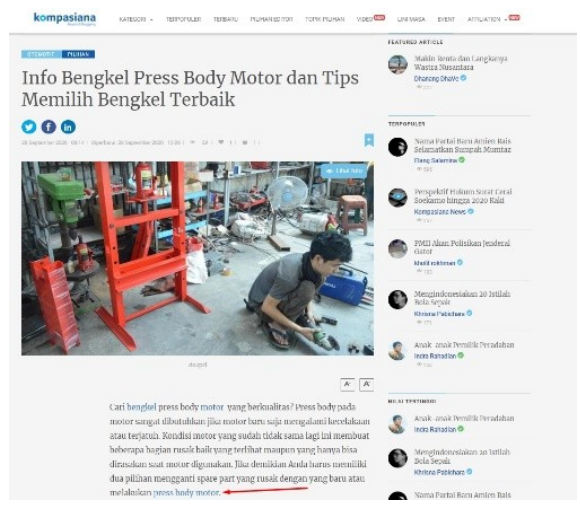

Gambar 15. Artikel di Kompasiana

Pada gambar di atas, terdapat sebuah link di dalam artikel yang mengarah ke situs www.superbengkel.co.id

e. Memposting artikel di PBN (Private Blog Network)

Langkah terakhir adalah memposting artikel di Private Blog Network (PBN).
PBN bukan seperti blog pada umumnya, melainkan blog yang sudah berumur dan memiliki otoritas domain yang tinggi. Maka dari itu, backlink yang dihasilkan dari PBN dapat meningkatkan rangking website. Contoh penerapannya seperti artikel yang diposting di salah satu blog PBN berikut:

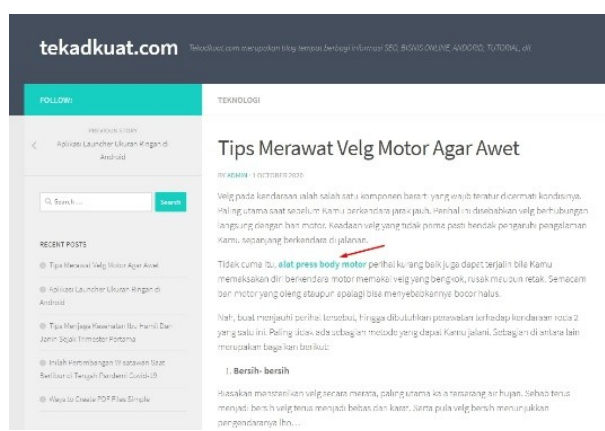

Gambar 16. Artikel di Blog PBN

\subsection{Hasil Optimasi}

a. Analisis Hasil SEO Onpage

Pada tahap ini dilakukan pengujian terhadap optimalisasi halaman website terutama dalam hal kecepatan website. Pengujian dilakukan menggunakan tools PageSpeed Insight milik Google beralamat https://developers.google.com/speed/pa gespeed/insights/

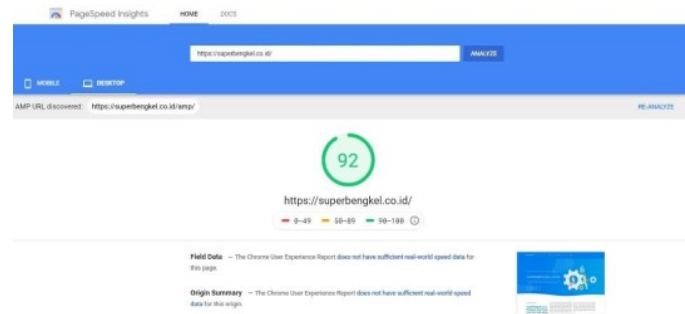

Gambar 17. Hasil Pengujian Kecepatan Loading Website 
Pada pengujian diatas menunjukkan bahwa situs www.superbengkel.co.id memiliki kecepatan loading website yang optimal yaitu dengan nilai 92/100.

b. Analisis Hasil SEO Offpage

Data hasil optimasi SEO Offpage dianalisis menggunakan Google Webmaster Tools. Data dianalisis dari awal proses optimasi yaitu tanggal 1 Juli 2020 hingga 15 Oktober 2020. Hasil analisis meliputi:

1) Total Clicks jumlah postingan yang diklik oleh pengguna pada hasil pencarian google dengan nilai sebesar 280 klik.

2) Total Impressions adalah jumlah yang menunjukan postingan website ditemukan di hasil pencarian sesuai dengan query yang digunakan. Dalam hal ini nilai Total Impressions sebesar 1550.

3) Average CTR (Click Throught Rate) adalah rata-rata persentase hasil bagi antara jumlah klik dibagi dengan jumlah impression di kali 100\%. Dalam hal ini nilai Avg. CTR sebesar $18 \%$.

4) Average position adalah informasi mengenai rata-rata urutan posisi judul postingan website ditemukan pada halaman hasil pencarian google, semakin kecil nilai Average position posisi website semakin baik pada hasil pencarian google. Dalam hal ini nilai Average position sebesar 19.8.

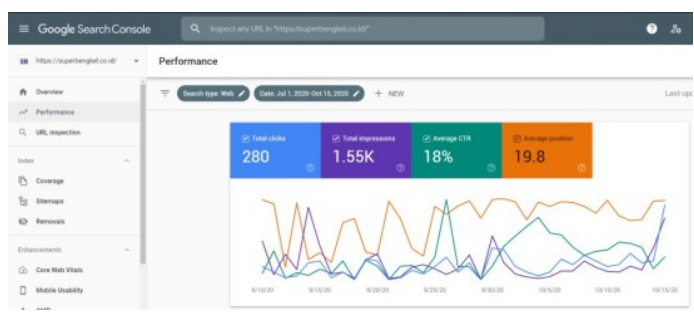

Gambar 18. Hasil Analisis SEO

Offpage Menggunakan Google

Webmaster Tools

c. Analisis Hasil Pencarian Google Setelah tahap SEO Onpage dan SEO Offpage selesai dilakukan, berikutnya adalah menguji dan menampilkan data hasil pencarian kata kunci yang ditargetkan di mesin pencari google. Berikut screenshot hasil pencarian kata kunci "Setup Bengkel”, "Harga Press Body Motor" dan "Jasa Press Velg Motor" pada mesin pencari google:

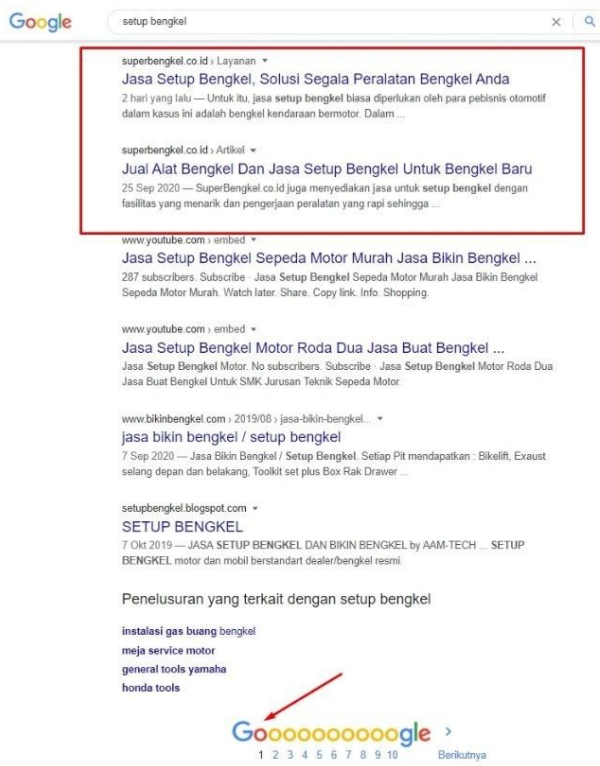

Gambar 19. Hasil Pengujian Kata Kunci "Setup Bengkel” 
Pada gambar 17. menunjukkan hasil optimasi terhadap kata kunci "setup bengkel" dengan memperoleh posisi ke-5 pada halaman pertamagoogle.

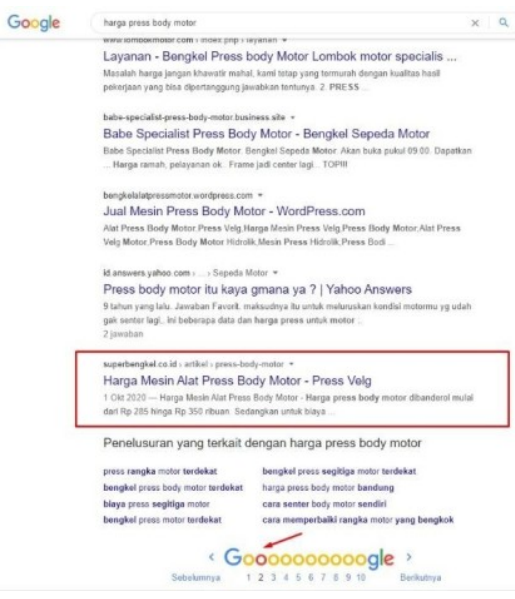

Gambar 20. Hasil Pengujian Kata

Kunci "Harga Press Body Motor"

Pada gambar 18 menunjukkan hasil optimasi terhadap kata kunci "Harga Press Body Motor" dengan memperoleh posisi ke-6 pada halaman kedua google.

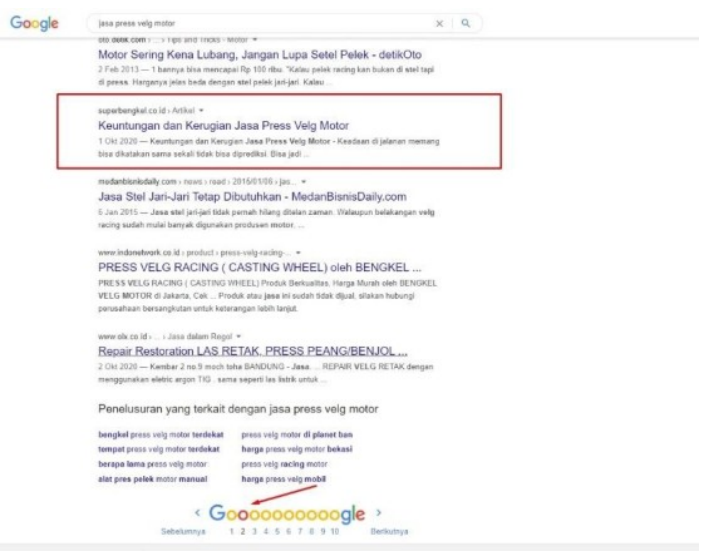

Gambar 21. Hasil Pengujian Kata

$$
\text { Kunci "Jasa Press Velg Motor" }
$$

Pada gambar 19 menunjukkan hasil optimasi terhadap kata kunci "Jasa Press Velg Motor" dengan memperoleh posisi ke-10 pada halaman kedua google. Berikut perbandingan posisi kata kunci yang ditargetkan pada situs www.superbengkel.co.id sebelum diterapkannya SEO dan setelah diterapkannya SEO pada tabel di bawah ini:

Tabel 2. Posisi Kata Kunci Sebelum dan Sesudah Menggunakan SEO

\begin{tabular}{|c|c|c|}
\hline $\begin{array}{c}\text { Kata } \\
\text { Kunci }\end{array}$ & $\begin{array}{c}\text { Sebelum SEO } \\
\text { (1 Juli 2020) }\end{array}$ & $\begin{array}{c}\text { Setelah SEO } \\
\text { (15 Oktober 2020) }\end{array}$ \\
\hline $\begin{array}{c}\text { Setup } \\
\text { Bengkel }\end{array}$ & $>100$ & 5 \\
\hline $\begin{array}{c}\text { Harga } \\
\text { Press Body } \\
\text { Motor }\end{array}$ & $>100$ & 20 \\
\hline $\begin{array}{c}\text { Jasa Press } \\
\text { Velg }\end{array}$ & $>100$ & 16 \\
Motor & & \\
\hline
\end{tabular}

Sumber: Google.com (2020)

Dari tabel di atas menunjukkan bahwa peringkat kedua kata kunci yang ditargetkan pada situs www.superbengkel.co.id sebelumnya masih diatas 100, mengalami peningkatan setelah diterapkannya SEO.

\section{Kesimpulan}

Dari hasil penelitian di atas, maka diambil kesimpulan bahwa SEO manjadi faktor penting dalam meningkatkan rangking kata kunci sebuah website pada hasil pencarian di google. Walaupun belum maksimal, namun hal ini cukup membuktikan bahwa SEO mempunyai pengaruh yang signifikan.

Beberapa saran yang perlu diperhatikan adalah website harus terus diupdate secara 
berkala dari sisi konten atau artikel. Hal ini dilakukan supaya website dapat mempertahankan bahkan meningkatkan peringkatnya pada hasil pencarian google

\section{Daftar Pustaka}

[1] Abdurrahman. 2014. Analisis Pengaruh Kata Kunci Kompetitif Pada Search Engine Optimization (SEO) Terhadap Pemasaran Online Untuk Produk Notebook. Jurnal Ilmiah Informatika Komputer Universitas Gunadarma Vol 19, No 3. Hal 73-80.

[2] Aini, Addinda Qorri dan Joni Dwi Pribadi. 2017. Pembuatan Website Menggunakan Cms Wordpress Sebagai Media Promosi Pada Rumah Crochet Batu. Jurnal Aplikasi Bisnis Vol 3, No 1. Hal 287-292.

[3] Himawan, dkk. 2015. Analisa Pengaruh Penggunaan Search Engine Optimization (SEO) Pada Website ECommerce. Seminar Nasional Sistem Informasi Indonesia 2-3 November 2015.

[4] Laksana, Tri Ginanjar dan Elfa Syahara. 2018. Analisis Perbandingan Performance Search Engine Berdasarkan 1 - 5 Suku Kata Kunci Menggunakan Strategi Phrase, Multiple Search, Pencarian Field \& Penggunaan Symbol. Seminar
Nasional Sistem Informasi Indonesia 5 November 2018.

[5] Riyanto, Andi Dwi dan Purwadi. 2016. Penerapan Teknik Search Engine Optimization (SEO) untuk Memenangkan Persaingan Kata Kunci pada Mesin Pencari Google (Studi Kasus: Paguyuban Pengrajin Alas Kaki SIMBA Purwokerto, Banyumas). JUITA: Jurnal Informatika Vol. IV Nomor 2. Hal 5965.

[6] Sutanto, Felix Andreas dan Sri Mulyani. 2015. Implementasi Search Engine Optimization (SEO) On Page Pada Web Umkm Batik Dan Handicraft. Prosiding Seminar Nasional Multi Disiplin Ilmu \& Call For Papers Unisbank (Sendi_U), Kajian Multi Disiplin Ilmu untuk Mewujudkan Poros Maritim dalam Pembangunan Ekonomi Berbasis Kesejahteraan Rakyat.

[7] http://www.alexa.com/topsites/countri es/ID, diakses 1 Juni 2020

[8] https://www.similarweb.com/topwebsites, diakses 1 Juni 2020 